AperTO - Archivio Istituzionale Open Access dell'Università di Torino

\title{
COUP-TFI controls activity-dependent tyrosine hydroxylase expression in adult dopaminergic olfactory bulb interneurons
}

\section{This is the author's manuscript}

Original Citation:

Availability:

This version is available http://hdl.handle.net/2318/139717

since 2015-12-31T13:55:26Z

Published version:

DOI:10.1242/dev.089961

Terms of use:

Open Access

Anyone can freely access the full text of works made available as "Open Access". Works made available under a Creative Commons license can be used according to the terms and conditions of said license. Use of all other works requires consent of the right holder (author or publisher) if not exempted from copyright protection by the applicable law. 


\section{(8) \\ UNIVERSITÀ DEGLI STUDI DI TORINO}

This is an author version of the contribution published on:

Questa è la versione dell'autore dell'opera:

[DEVELOPMENT, 140(24), 2013, doi: 10.1242/dev.089961]

ovvero [Bovetti S., Bonzano S., Garzotto D., Giannelli S.G., Iannielli A., Armentano M., Studer M., De Marchis S., 140(24), Company of Biologists, 2013, 4850-4859]

The definitive version is available at:

La versione definitiva è disponibile alla URL:

[http://dev.biologists.org/content/140/24/4850.long] 


\title{
COUP-TFI controls activity-dependent TH expression in adult dopaminergic olfactory bulb interneurons
}

\author{
Serena Bovetti ${ }^{1,{ } *}$, Sara Bonzano ${ }^{1,2} *$, Donatella Garzotto ${ }^{1}$, Serena Gea Giannelli ${ }^{3}$, Angelo \\ Iannielli $^{1,2}$, Maria Armentano ${ }^{2,4}$, Michèle Studer ${ }^{4,5,6}$ and Silvia De Marchis ${ }^{1,2}$
}

${ }^{1}$ Dept. of Life Sciences and Systems Biology, University of Turin, Italy; ${ }^{2}$ Neuroscience Institute Cavalieri Ottolenghi (NICO), Orbassano, Turin, Italy; ${ }^{3}$ San Raffaele Scientific Institute, Milan, Italy; ${ }^{4}$ Telethon Institute of Genetics and Medicine (TIGEM), Naples, Italy; ${ }^{5}$ University of Nice Sophia-Antipolis, F-06108 Nice, France; ${ }^{6}$ INSERM UMR 1091, F-06108, Nice, France.

*first co-authors

${ }^{\S}$ current address: Dept. of Neuroscience and Brain Technologies, Italian Institute of Technology (IIT), Genova, Italy.

\section{Corresponding author:}

Silvia De Marchis, $\mathrm{PhD}$

University of Turin,

Dept. Life Sciences and Systems Biology (DBIOS)

Via Accademia Albertina, 13 - 10123 Torino - IT

Neuroscience Institute Cavalieri Ottolenghi (NICO)

Regione Gonzole, 10 - 10043 Orbassano (To) - IT

Ph. +390116704674/6605

Fax +390116704508

Email: silvia.demarchis@unito.it

Keywords: juxtaglomerular cells; tyrosine hydroxylase (TH); Emx1-lineage; sensory deprivation;

Zif268.

Short title: COUP-TFI function in the OB

Acknowledgements: We are grateful to C. Giachino and O. Benedetto for participation in an initial stage of the project; to V. Broccoli for support in the lentiviral experiments; to K. Kobayashi for the TH-GFP mice; to O. Friard for help in the in silico analysis; to J. Cave, A. Fasolo and P. Peretto for fruitful discussions.

Funding: This work was supported by PRIN 2009 prot. 2009TBCZJB_004; Compagnia di San Paolo, Italy (Neurotransplant 2007-0660; Program of Neuroscience 2008-1135 to M.S.); Italian Telethon Foundation and the ANR "2009 Chaires d'Excellence" Program, France, under grant number R09125AA to M.S. S. Bovetti was recipient of a fellowship sponsored by Regione Piemonte Azione A.

Author Contribution: Se.B., S.D.M. and M.S. jointly coordinated and designed this work and wrote the manuscript. Se.B, S.D.M. and Sa.B. conducted experiments and analysis on COUPTFIfl/fl $^{\text {Emxl-Cre }}$ and COUP-TFIfl/flx5/6-Cre mouse lines. Se.B. conducted BrdU and olfactory deprivation experiments and analysis; Sa.B and S.D.M. conducted viral injections and olfactory stimulation experiments; Sa.B. performed confocal analysis and prepared the figures of the paper. D.G. and A.I. conducted immunohistochemical analysis; M.A. e M.S. contributed with generation of COUP-TFI $f l / f l$ mice and tissue preparation from COUP-TFI $f l / f l$ derived lines; S.G. produced the lentiviral vectors. 


\section{ABSTRACT}

COUP-TFI is an orphan nuclear receptor acting as a strong transcriptional regulator in different aspects of forebrain embryonic development. In this study, we investigated COUP-TFI expression and function in the mouse olfactory bulb (OB), a highly plastic telencephalic region in which continuous integration of newly generated inhibitory interneurons occurs throughout life. OB interneurons belong to different populations that originate from distinct progenitor lineages. Here, we show that COUP-TFI is highly expressed in tyrosine hydroxylase (TH)-positive dopaminergic interneurons in the adult $\mathrm{OB}$ glomerular layer (GL). We found that odour deprivation, which is known to down-regulate TH expression in the OB, also down-regulates COUP-TFI in dopaminergic cells, indicating a possible correlation between TH and COUP-TFI activity-dependent action. Moreover, we demonstrate that conditional inactivation of COUP-TFI in the Emx1-lineage results in a significant reduction of both TH and expression of the immediate early gene Zif268 in the GL. Finally, lentiviral vector-mediated COUP-TFI deletion in adult generated interneurons confirmed that COUP-TFI acts cell autonomously in the control of TH and Zif268 expression. These data indicate that COUP-TFI regulates $\mathrm{TH}$ expression in $\mathrm{OB}$ cells through an activity-dependent mechanism involving Zif268 induction and strongly argue for a maintenance rather than establishment function of COUP-TFI in DAergic commitment. Our study reveals a previously unknown role for COUP-TFI in the adult brain as a key regulator in the control of sensorydependent plasticity in olfactory dopaminergic neurons. 


\section{INTRODUCTION}

In the olfactory bulb (OB), a rich and heterogeneous population of glomerular layer (GL) interneurons participates in the first steps of olfactory information processing by modulating the activity of the $\mathrm{OB}$ output neurons, the mitral/tufted cells. Most juxtaglomerular cells are GABAergic and can be classified into different subclasses based on the expression of specific neurochemical markers and the connection networks they establish within the GL (Parrish-Aungst et al., 2007; Kosaka and Kosaka, 2007; Kiyokage et al., 2010). For example, calbindin-positive $(\mathrm{CB}+)$ and calretinin-positive $(\mathrm{CR}+)$ cells are activated by the inputs from the mitral/tufted dendrodendritic synapses and are involved in local intraglomerular circuits. Cells expressing tyrosine hydroxylase (TH), the rate-limiting enzyme for dopamine (DA) synthesis, in addition to inputs from mitral/tufted cells, also receive direct synaptic inputs from the olfactory nerve terminals and can be involved in either intraglomerular or interglomerular (long-range) connections (Kiyokage et al., 2010). Although TH+ DAergic interneurons represent only the 10-15\% of juxtaglomerular cells, they correspond to a population of particular interest in the OB. They play a key role in olfactory perception, discrimination and learning (Cave and Baker, 2009). Interestingly, TH expression and consequently DA release in GL interneurons depend on afferent synaptic activity and are strongly reduced following olfactory deprivation. This activity-dependent regulation of $\mathrm{TH}$ has been related to a possible role of DA in the modulation of odorant information processing in response to either high or low levels of afferent odour-induced synaptic activity (Cave and Baker, 2009).

As for other OB interneurons, the generation of DAergic cells initiates during embryonic ages and continues throughout life from spatially restricted pool of stem/progenitor cells (Luskin, 1993; De Marchis et al., 2007; Young et al., 2007; Merkle et al., 2007; Batista-Brito et al., 2008). The earliest generated DAergic cells are locally derived from stem cells in the prospective OB (Vergaño-Vera et al., 2006), while starting from mid-embryonic development, DAergic cells largely originate from subventricular zone (SVZ) and rostral migratory stream (RMS) progenitors that 
mostly belong to the Dlx5/6- (LGE-derived) or Emx1- (cortex-derived) lineages at different ratio and depending on age (Hack et al., 2005; Kohwi et al., 2007; Young et al., 2007). Although several genes involved in the specification and differentiation of the OB DAergic neurons, including Pax6, Dlx2 and Er81, have been identified (Hack et al., 2005, Brill et al., 2008; de Chevigny et al., 2012, Saino-Saito et al., 2007, Cave et al., 2010), the complexity of the molecular genetic regulation of OB DAergic interneurons is far to be elucidated.

In this study, we analysed the function of the chicken ovalbumin upstream promoter transcription factor I (COUP-TFI, also known as NR2F1) in olfactory DAergic neurons. COUPTFI, a member of the orphan nuclear receptor family, plays multiple roles in neuronal development (Park et al., 2003; Alfano et al., 2013). It is highly expressed in the developing telencephalon (Qui et al., 1994; Armentano et al., 2006), where it regulates the balance of cortical patterning between frontal/motor and sensory areas (Armentano et al., 2007), and is involved in the migration and specification of cortical GABAergic interneurons in the subpallium (Tripodi et al., 2004; Lodato et al., 2011). Here, we show that COUP-TFI is co-expressed with TH in the vast majority of DAergic neurons in the $\mathrm{OB}$, in an activity-dependent manner. By means of genetic ablation of COUP-TFI function in Emx1- and Dlx5/6- progenitor lineages, we provide evidence that in the adult OB, COUP-TFI acts selectively in Emx1-derived interneurons controlling the expression of TH and of the immediate early gene Zif268 (also known as egr-1 or NGFI-A, Knapska and Kaczmarek, 2004). Finally, by cell autonomous manipulations in adult RMS progenitors, we demonstrate a COUP-TFI intrinsic function in the control of TH and Zif268 expression in the adult OB.

\section{MATERIAL AND METHODS}

Animals: COUP-TFI-floxed (COUP-TFIfl/fl) mice were generated and genotyped as previously described (Armentano et al., 2007). These mice were either crossed to Dlx5/6-IRES-Cre (Stenman et al., 2003) or to Emxl-IRES-Cre (Gorski et al., 2002) to generate mice homozygous for COUPTFIfl/fl and heterozygous for Dlx5/6-IRES-Cre (COUP-TFIfl/fl $\left.{ }^{\text {Dlx5/6-Cre }}\right)$ or Emx1-IRES-Cre (COUP- 
TFIfl/fl $^{\text {Emxl-Cre }}$ ). COUP-TFIfl/+ or COUP-TFIfl/fl mice were used as controls, and the latter also for injections of lentiviral vectors. All lines were maintained in a C57BL/6J genetic background. THGFP mice carrying the GFP under the control of TH promoter (Sawamoto et al., 2001; Matsushita et al., 2002) were maintained as heterozygous by breeding with C57BL/6J inbred mice. C57BL/6J wild-type mice were used for olfactory deprivation (Charles River). C57BL/6J mice at post-natal (P) day 0, 7, 14 or 21 were also evaluated, together with a group of P7 COUP-TFI $f l f l^{\text {Emxl-Cre }}$ mice. Animals were housed under a 12-hour light-dark cycle in an environmentally controlled room. Experimental procedures were in accordance with the European Communities Council Directive of 24 November 1986 (86/609 EEC), Recommendation 18/06/2007, Dir. 2010/63/UE, and the Italian law for care and use of experimental animals (DL116/92) and were approved by the Italian Ministry of Health and the Bioethical Committee of the University of Turin.

Olfactory deprivation: Adult mice ( 8 weeks old males; $n=10$ ) were lightly anesthetized with a mixture of ketamine (Ketavet; Gellini) and xylazine (Rompun; Bayer) before inserting the nose plugs (polyethylene tubing, $0.7 \mathrm{~mm}$ ) into the right naris for 42 days. Olfactory deprivation effectiveness was checked post-mortem by controlling that the nose plug was retrieved in the anterior part of the snout and by confirming decreased levels of $\mathrm{TH}$ expression in the OB through immunofluorescence (Baker et al., 1993). Animals in which the plug was not retrieved or failed to show decreased TH expression, were discarded.

BrdU administration: Adult mice ( 8 weeks old males; n=14) received four injections, 4 hours apart, of 5-bromo-2-deoxyuridine (BrdU; 50 mg/kg in 0.1 M Tris, pH 7.4; Sigma) and were euthanized 42 days later.

Viral production: The lentiviral constructs include either an ires-GFP (lenti-iGFP) or a Cre recombinase-ires-GFP (lenti-CRE-iGFP) cassette under the control of a CMV promoter. 
Replication-incompetent, VSVg-coated lentiviral particles were packaged in 293T cells. Cells were transfected with $30 \mu \mathrm{g}$ of vector and packaging constructs, according to a conventional $\mathrm{CaCl}_{2}$ transfection protocol. After $30 \mathrm{~h}$, medium was collected, filtered through $0.22 \mu \mathrm{m}$ cellulose acetate and centrifuged at $20000 \mathrm{rpm}$ for $2 \mathrm{~h}$ at $20^{\circ} \mathrm{C}$ in order to concentrate the virus. The titer was evaluated by infecting $293 \mathrm{~T}$ cells with serial dilution of the virus and assessed as the lower concentration at which fluorescent cells were still detectable. In all preparations the virus titer was in the order of $10^{7} \mathrm{ifu} / \mathrm{ml}$.

Stereotaxic injections: Adult COUP-TFIfl/fl or C57BL/6J mice (8-12 weeks old, $\mathrm{n}=14)$ were used. Mice were anesthetized with an intraperitoneal injection of a mixture of ketamine (Ketavet; Gellini) and xylazine (Rompun; Bayer) and placed on a stereotaxic apparatus. Bilateral injections into the RMS were performed at the following coordinates: mediolateral, $\pm 0.8 \mathrm{~mm}$ and anteroposterior, +3.1 $\mathrm{mm}$ to Bregma; and $-2.9 \mathrm{~mm}$ from the pial surface (modified from Pallotto et al., 2012). Each mouse received two injections: a control injection in the right RMS (lenti-iGFP) and a Cre-mediated COUP-TFI ablating injection in the left RMS (lenti-CRE-iGFP). Viral vector particles (diluted 1:4 into $1 \mu \mathrm{l} 0.9 \%$ saline solution) were slowly injected using a glass micropipette and a pneumatic pressure injection apparatus (Picospritzer II, General Valve Corp, Fairfield, IL). Animals were then placed into breeding standard cages and monitored until they resumed feeding and grooming activity, and sacrificed 30 or 60 days post-injection (dpi).

Olfactory stimulation: 8-12 weeks old, COUP-TFIfl/+ or COUP-TFIfl/fl ${ }^{\text {Emxl-Cre }}$ mice, $(\mathrm{n}=13)$ were housed under standard conditions. The day prior to the experiment, animals were individually separated in acrylic filtering-covered cages to reduce background activity (Magavi et al., 2005). Before euthanasia, awake and alert mice (stimulated group, named "stim") underwent the odour stimulation individually in a clear cage without food and water. A 30-minutes exposure to a mixed set of natural odours (banana, lemon peel, basil, lavender, cloves; Modified from Magavi et al., 
2005; Vincis et al., 2012) was used to obtain a diffuse and scattered activation in the OB. Odours were placed in a tea ball hanging from the acrylic filtering cover. Animals were then placed in a clear standard breeding cage for additional 30 minutes before euthanasia. Non-stimulated groups for each genotype (named "basal") were treated under the same conditions except that the tea ball was left empty.

Tissue preparation: Postnatal ( $\mathrm{P} 7, \mathrm{P} 14, \mathrm{P} 21)$ and adult mice were anesthetized with an intraperitoneal injection of a mixture of ketamine (Ketavet; Gellini) and xylazine (Rompun; Bayer) and perfused transcardially with $0.9 \%$ saline solution, followed by $4 \%$ paraformaldehyde (PFA) in 0.1 M phosphate buffer (PB), $\mathrm{pH}$ 7.4. Brains were removed from the skull, postfixed for 6 hours in the same solution, cryoprotected in a $30 \%$ sucrose solution in $0.1 \mathrm{M} \mathrm{PB}, \mathrm{pH} 7.4$, frozen and cryostat sectioned (Leica Microsystems, Milan, Italy). Free-floating coronal serial sections $(25 \mu \mathrm{m})$ were collected in multiwell dishes. Sections were stored at $-20^{\circ} \mathrm{C}$ in antifreeze solution until use. P0 mice were anesthetized by hypothermia and their brain dissected and fixed by immersion overnight in a solution of $4 \%$ PFA in $0.1 \mathrm{M} \mathrm{PB}, \mathrm{pH}$ 7.4. Specimens were then processed as described above except of cryostat coronal sections $(14 \mu \mathrm{m})$, which were collected in series directly on glass slides.

Immunohistochemistry and immunofluorescence: Sections were incubated overnight at $4^{\circ} \mathrm{C}$ in primary antibody diluted in $0.01 \mathrm{M}$ PBS (pH 7.4), 0.01-0.5\% Triton X-100, and 1\% normal serum of the same species of the secondary antibody, and then incubated for 1 hour at room temperature (RT) in the appropriate secondary antibody. For BrdU immunostaining, sections were pre-treated with $2 \mathrm{~N} \mathrm{HCl}$ and neutralized with borate buffer $(\mathrm{pH} \mathrm{8.5)} \mathrm{before} \mathrm{anti-BrdU} \mathrm{staining.} \mathrm{Sections} \mathrm{were}$ then mounted on gelatine-coated slides, air dried, and cover-slipped in polyvinyl alcohol with diazabicyclo-octane (DABCO). For the avidin-biotin-peroxidase (BAS) method, sections were incubated for $1 \mathrm{~h}$ at RT in secondary biotinylated antibody, followed by the avidin-biotinperoxidase complex and developed by incubation in $0.015 \%$ 3,3'-diaminobenzidine (DAB) and 
$0.0024 \% \mathrm{H}_{2} \mathrm{O}_{2}$ in $0.05 \mathrm{M}$ Tris- $\mathrm{HCl}, \mathrm{pH}$ 7.6. Slices were mounted on gelatine-coated slides, air dried, and covered in DPX Mountant (Sigma-Aldrich). The following primary antibodies were used: anti-BrdU (1:5000, IFL; 1:10000, BAS; rat; AbD Serotec), anti-calbindin D-28K (CB) (1:1000; rabbit; Swant), anti-CR (1:8000; rabbit; Swant), anti-CR (1:8000; mouse; Swant), anti-TH (1:2000; rabbit; Institut Jacques Boy, France), anti-TH (1:3000; mouse; Immunostar), anti-COUPTFI (1:500; mouse; R\&D Systems), anti-COUP-TFI (1:500; rabbit; Tripodi et al., 2004), anti-Pax6 (1:3000; rabbit; Chemicon), anti-Er81 (1:15000, IFL; 1:20000, BAS; rabbit; a gift from T. Jessell), anti-GFP (1:1000; chicken, Aves Lab), anti-DCX (1:500; goat, Santa Cruz), anti-NeuN (1:1000; mouse, Chemicon), anti-Cre recombinase (1:1500; rabbit; Covance), anti-Zif268 (egr-1) (1:500; rabbit; Santa Cruz). Secondary antibodies were used as follows: anti-mouse, anti-rabbit and anti-rat Cy3-conjugated (1:800; Jackson ImmunoResearch); anti-rabbit and anti-mouse AlexaFluor 647conjugated (1:600; Jackson ImmunoResearch); anti-goat, anti-rat and anti-rabbit biotinylated (1:250; Vector) followed by avidin-FITC incubation (1:400; Jackson ImmunoResearch) or avidinbiotin-peroxidase complex (Vector); anti-rabbit and anti-rat AlexaFluor 488-coniugated (1:400; Molecular Probes); anti-chicken AlexaFluor 488-conjugated (1:400; Jackson ImmunoResearch). Co-localization between COUP-TFI and GAD67 was analysed on adult Gad67-GFP mice expressing GFP under the control of the endogenous GAD67 gene promoter (Tamamaki et al., 2003), kindly provided by Prof. F. Rossi (University of Turin).

Microscopy and quantification: Cell counts were conducted blind. Cell counting and image analysis were performed on either a Nikon microscope coupled with a computer-assisted image analysis system (Neurolucida software, MicroBrightField), a Fluo-View 500 confocal microscope (Olympus Instruments) or a TCS SP5 confocal microscope (Leica). Confocal image z-stacks were captured through the thickness of the slice at $1 \mu \mathrm{m}$ optical steps and used for double- or triple-labelled cell counts. To estimate the volume of each layer, camera lucida drawings of sections were performed through the entire OB. The boundaries between layers were estimated from changes in cell density 
in sections stained with the nuclear dye 4',6-diamidino-2-phenylindole (DAPI). The area of each section and layer was automatically calculated by Neurolucida software and the volume of the layers estimated applying the Cavalieri method (Prakash et al., 1994). Densities of positive cells were calculated applying a random sampling method using a virtual counting grid. Cells were counted through the thickness of the slice in one pre-selected square by sequential translation of the counting grid until the entire layer of interest was covered. Cell density (D) was calculated using the formula $\mathrm{D}=(\mathrm{N} * 4) / \mathrm{A}^{*} 10^{6}$, where $\mathrm{N}$ is the number of positive cells counted using the grid and $\mathrm{A}$ is the layer area $\left(\mu \mathrm{m}^{2}\right)$ and expressed as the number of positive cells per $\mathrm{mm}^{2}$. Total cell number estimation ( $T$ ) was calculated using the formula $T=D * V / t$ where $D$ is the cell density, $V$ is the volume of the whole GL and the thickness of the section analysed. Statistical comparisons were conducted by Student's t-test, one-way or two-way ANOVA followed by Tukey post-hoc comparison, where appropriate. Significance was established at $\mathrm{p}<0.05$. Cell counts and volumes are presented as mean \pm standard error of the mean (s.e.m.) and are derived from at least three different animals, analysing at least three OB sections (at anterior, medial and posterior levels) for each animal.

\section{RESULTS}

\section{COUP-TFI is expressed in mature DAergic olfactory interneurons}

COUP-TFI expression in the adult OB was investigated by immunofluorescence (Fig. 1). Intense COUP-TFI nuclear immunolabelling was found in cells mostly localized in the OB GL and granule cell layer (GcL). In the GL most immunopositive nuclei showed intense labelling, whereas in the GcL COUP-TFI+ nuclei displayed a wide range of staining intensity, from strong to very low (Fig. 1A). To further characterize COUP-TFI+ positive cells in the OB, we performed double labelling for COUP-TFI and either NeuN (Fig.1B) or doublecortin (DCX; Fig.1C). The neuronal specific nuclear protein $\mathrm{NeuN}$ is expressed by all mature granule cells in the GcL and by a subset of mature cells in the GL (Bagley et al., 2007), while DCX is expressed by all SVZ-derived neuroblasts and 
progressively down-regulated as interneurons mature (Brown et al., 2003). The large majority of COUP-TFI+ cells was co-labelled for NeuN in the GcL $(85.7 \pm 3.5 \% ; n=323$ cells $)$ and nearly $52 \%$ of COUP-TFI+ cells did express NeuN in the GL $(52.4 \pm 3.2 \%$; $=330$ cells $)$. On the other hand, COUP-TFI+ cells were rarely detected in the core of the OB (Fig. 1B,C, asterisks), where the migratory stream of DCX+ SVZ-derived neuroblasts enters the bulb (Fig. 1C). About 7\% (7.4 \pm $1.7 \% ; n=586$ cells $)$ and $4 \%(3.7 \pm 0.4 \% ; n=510$ cells $)$ of COUP-TFI+ cells were double positive for DCX in the GcL and GL respectively, indicating little COUP-TFI labelling in immature cells. Thus, COUP-TFI expression in the OB is mostly associated to mature neurons.

It is known that most cells in the GL and GcL are GABAergic interneurons (Parrish-Aungst et al., 2007). Analysis of Gad67-GFP mice (Tamamaki et al., 2003; Fig. 1D) showed that virtually all COUP-TFI+ cells in the OB were co-labelled with GFP $(92.24 \pm 1.64 \%$; $n=338$ cells $)$; however, COUP-TFI+ cells represent only a subset of the GABAergic GFP+ cells. We thus focused on the GL to understand whether COUP-TFI expression was associated to specific neurochemical phenotypes by analyzing double-labelled neurons for COUP-TFI and CR, CB or TH (Fig. 1E-G). Only few cells were double labelled with COUP-TFI and CR or CB (CR+/COUP-TFI+: $0.96 \pm$ 0.21\%; n=591 cells; CB+/COUP-TFI+: $2.15 \pm 0.20 \%$; n=284 cells; Fig. 1E, F). On the other hand, about $71 \%$ of COUP-TFI+ cells were positive for TH (Fig. 1G,P-Adult). The fraction of COUPTFI+ cells that were negative for TH might instead be juxtaglomerular cells of an unknown phenotype or, alternatively, might belong to DAergic precursor cells in which the transcription of the TH gene occurs with no significant translational activity (Baker et al., 2001). To test this latter hypothesis, we studied COUP-TFI distribution in the OB of a transgenic line expressing GFP under the TH promoter (Sawamoto et al., 2001; Matsushita et al., 2002; Fig. 1H), and found that almost $83 \%$ of COUP-TF+ cells were also GFP+ $(83.06 \pm 1.62 \% ; n=1537$ cells $)$. In addition, all COUPTFI+ cells in the adult OB GL were also positive for Pax6 ( $n=516$ cells; Fig. 1I), a major determinant factor of the DAergic phenotype (Kohwi et al., 2005; Hack et al., 2005; de Chevigny et al., 2012). Notably, 90\% of Pax6+ $(89.43 \pm 3.62 \% \mathrm{n}=577$ cells $)$ and nearly $80 \%$ of $\mathrm{TH}+$ olfactory 
interneurons do express COUP-TFI (Fig. 1Q-Adult), indicating high association between this transcription factor and the DAergic phenotype.

Next, we analysed COUP-TFI expression in DAergic cells during OB postnatal development (postnatal ages: P0, P7, P14, P21; Fig. 1J-M). Quantification of TH+ cells in the developing OB showed a 20-fold increase from P0 to adult age (one-way ANOVA, $\mathrm{F}_{(4,13)}=105.57$, $\mathrm{p}<0.001$; Fig. $1 \mathrm{~N})$, with a drastic expansion of the $\mathrm{TH}+$ population starting from the second postnatal week. A similar pattern was observed for COUP-TFI+ cells (one-way ANOVA, $\mathrm{F}_{(4,13)}=251.11, \mathrm{p}<0.001$; Fig. 1O). Double labelling analysis showed that as for adult mice, also in newborn or young animals, a substantial fraction (ranging from 70 to $80 \%$ ) of the COUP-TFI+ population was double positive for $\mathrm{TH}$ (Fig. 1P). Interestingly, the percentage of $\mathrm{TH}+$ cells expressing COUP-TFI in the OB changed with time. In the first postnatal week the large majority of $\mathrm{TH}+$ cells were negative for COUP-TFI (Fig. 1Q). Conversely, 55\% and $62 \%$ of TH+ cells expressed COUP-TFI at P14 and P21, respectively, which further increased to $80 \%$ in adult mice (one-way ANOVA, $\mathrm{F}_{(4,13)}=908.52$, $\mathrm{p}<0.001$; Fig. 1Q), confirming that expression of COUP-TFI is associated to DAergic cells generated during late postnatal and adult life.

\section{Sensory input regulates COUP-TFI expression in olfactory DAergic cells}

It is well known that TH expression in DAergic cells depends on afferent synaptic activity and that odour deprivation causes TH down-regulation (Baker et al., 1993). Since COUP-TFI is associated to mature DAergic cells, we asked whether odour deprivation could also affect COUP-TFI expression in the GL. To address this issue, odour deprivation was performed by unilateral naris closure and the total number of TH+ and COUP-TFI+ cells was estimated in control (Ctr) and deprived (Depr) mice 42 days after naris closure (Bovetti et al., 2009). As expected, a strong decrease in the number of $\mathrm{TH}+$ cells was observed in the OB ipsilateral to the closure (Ctr vs Depr: $t$-test $\mathrm{p}<0.001$; Fig. 2A-C). In parallel, we detected nearly $50 \%$ reduction of COUP-TFI+ neurons in the GL (Ctr vs Depr: $t$-test p<0.001; Fig. 2A,B,D). Accordingly, the number of double TH+/COUP- 
TFI+ labelled cells was significantly decreased $(71.48 \pm 0.87 \%$ in controls, $n=1558$ cells; $21.32 \pm$ $1.06 \%$ in deprived, $\mathrm{n}=1131$ cells; $t$-test $\mathrm{p}<0,001$; Fig. 2D), indicating that COUP-TFI downregulation occurred jointly with $\mathrm{TH}$ down-regulation. These data suggest possible implications of COUP-TFI function in the activity-dependent regulation of TH expression in DAergic cells.

\section{Genetic inactivation of COUP-TFI in the Emx1-lineage affects TH expression in adult} generated olfactory interneurons

To investigate the role of COUP-TFI in the DAergic phenotype, we chose a conditional genetic approach. We obtained mice lacking COUP-TFI in either the Dlx5/6- or the Emx1-lineage (i.e. two of the main lineages giving rise to OB interneurons; Kohwi et al., 2007; Young et al., 2007) by crossing the COUP-TFI-floxed line (COUP-TFfl/fl; Armentano et al., 2007) to either the Dlx5/6IRES-Cre (Stenman et al., 2003) or the Emxl-IRES-Cre (Gorski et al., 2002) transgenic lines. There was no apparent loss of COUP-TFI expression in the olfactory GL of COUP-TFIfl/fl ${ }^{\text {Dlx5/6-Cre }}$ mice (one-way ANOVA, $\mathrm{F}_{(2,10)}=82.845, \mathrm{p}<0.001$. fl/fl vs $f l / f l^{\text {Dlx5/6-Cre }}$, Tukey post-hoc $\mathrm{p}=0.469$; Fig. 3A,D,J). Similarly no changes were detected in the density of $\mathrm{TH}+$ cells in these animals (one-way ANOVA, $\mathrm{F}_{(2,8)}=32.009, \mathrm{p}<0,001 ; f l / f l$ vs $f l / f l^{\text {Dlx5/6-Cre }}$, Tukey post-hoc $\mathrm{p}=0.480$; Fig. 3B,E,K). On the contrary, mice in which COUP-TFI had been deleted in the Emx1-lineage showed a drastic reduction of COUP-TFI+ cells in the GL (one-way ANOVA, $\mathrm{F}_{(2,10)}=82.845$, $\mathrm{p}<0,001 ; f l / f l$ vs $f l / f l^{\text {Emxl-Cre }}$, Tukey post-hoc $\mathrm{p}<0.001 ;$ Fig. 3A,G,J), indicating that COUP-TFI-expressing juxtaglomerular cells mainly originate from the Emx1-lineage rather than from Dlx5/6-derived progenitors. However, no changes in the GL volume were observed $\left(1.8 \pm 0.01 \mathrm{~mm}^{3}\right.$ in $f l / f l$ mice and $1.8 \pm 0.06 \mathrm{~mm}^{3}$ in $f l / f l^{\text {Emxl-Cre }}$ mice, $t$-test $\left.\mathrm{p}=0.46\right)$. Importantly, analysis of $\mathrm{TH}$ immunofluorescence in the OB of COUP-TFIfl/fl $l^{\text {Emxl-Cre }}$ mice showed a net reduction in the density of $\mathrm{TH}+$ cells (one-way ANOVA, $\mathrm{F}_{(2,8)}=32.009, \mathrm{p}<0,001 ; f l / f l$ vs $f l / f l^{\text {Emxl-Cre }}$, Tukey post-hoc $\mathrm{p}<0.001$; Fig. 3B,H,K), which was lower than the one observed in COUP-TFI+ cells (Fig. 3J,K).

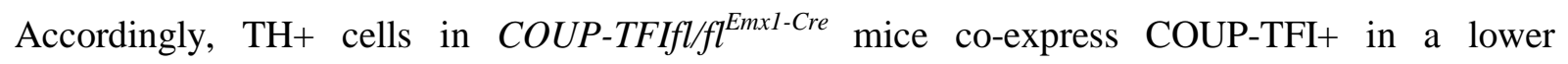


percentage compared to control mice $(26.56 \pm 1.73 \%$ of $\mathrm{TH}+$ cells were COUP-TFI+ in COUP-

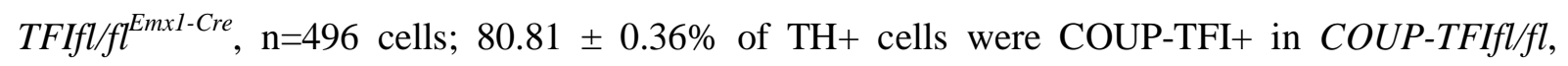
$\mathrm{n}=738$ cells; $t$-test $\mathrm{p}<0.001$; Fig. 3C,I), indicating that COUP-TFI ablation affects TH expression only in a subset of DAergic cells.

We next analysed COUP-TFI and TH expression in young postnatal (P7) COUP-TFIfl/fl ${ }^{\text {Emxl- }}$ Cre mice and found no changes in the density of both COUP-TFI+ and TH+ cells compared to control mice (COUP-TFI+: $732 \pm 38$ cells $/ \mathrm{mm}^{2}$ in $f l / f l$ and $688 \pm 20$ cells $/ \mathrm{mm}^{2}$ in $f l / f l^{\text {Emxl-Cre }}, t$-test $\mathrm{p}=0.43 ; \mathrm{TH}+: 677 \pm 91$ cells $/ \mathrm{mm}^{2}$ in $f l / f l$ and $497 \pm 14$ cells $/ \mathrm{mm}^{2}$ in $f l / f l^{\text {Emxl-Cre }}, t$-test $\left.\mathrm{p}=0.19\right)$. This suggests that COUP-TFI is not involved in TH regulation of early-generated DAergic cells deriving from the Emx1-lineage.

To further address the role of COUP-TFI in adult generated DAergic cells, we injected BrdU in 8 weeks old COUP-TFIfl/fl ${ }^{\text {Emxl-Cre }}$, COUP-TFIfl/fl ${ }^{\text {Dxx5/6-Cre }}$ and control mice to label newborn interneurons (Fig. 4A-C). At 42 days survival post BrdU injection, no changes in the overall BrdU+ cell density were observed in the GL among the different genotypes (one-way ANOVA, $\mathrm{F}_{(2,11)}=0.216, \mathrm{p}=0.809 ;$ Tukey post-hoc: $f l / f l$ vs $f l / f l^{\text {Dlx5/6-Cre }} \mathrm{p}=0.825 ; f l / f l$ vs $f l / f l^{\text {Emxl-Cre }} \mathrm{p}=0.998$; $f l / f l^{D l x 5 / 6-C r e}$ vs $f l / f l^{E m x l-C r e} \mathrm{p}=0.851$; Fig. 4A), indicating that lack of COUP-TFI does not affect adult generated interneuron survival. Next, we quantified the percentage of BrdU+ cells that expressed TH in COUP-TFIfl/fl ${ }^{\text {Emxl-Cre }}$ mice and found a 36,4\% reduction of double-labelled cells ( $t$-test $\mathrm{p}<0.05$; Fig. 4B,C), further supporting a role for COUP-TFI in the regulation of TH expression in adult generated cells.

We then asked whether absence of COUP-TFI function in the Emx1-lineage could also alter, besides TH, transcription factors, such as Pax6 and Er81, which are known to play a role in DAergic interneuron generation. No differences were found either in Pax6+ or Er81+ cell densities (Pax6+: $t$-test $\mathrm{p}=0.950 ;$ Er81+: $t$-test $\mathrm{p}=0.10 ;$ Fig. 4D,E) or in the percentages of BrdU+ cells double labelled for Pax6 or Er81 (Pax6+/BrdU+: $55.63 \pm 0.66 \%$ in $f l / f l, n=104$ cells; $56.40 \pm 3.37 \%$ in $f l / f l^{\text {Emxl-Cre }}, \mathrm{n}=99$ cells; $t$-test $\mathrm{p}=0.83 ;$ Er81+/BrdU+: $54.77 \pm 0.28 \%$ in $f l / f l, \mathrm{n}=115$ cells; $59.37 \pm$ 
$3.69 \%$ in $f l / f l^{\text {Emxl-Cre }}, \mathrm{n}=106$ cells; $t$-test $\left.\mathrm{p}=0.28\right)$. In parallel, analysis of $\mathrm{CR}+$ and $\mathrm{CB}+$ cells in the

GL of COUP-TFIfl/fl $\left.\right|^{\text {Emxl-Cre }}$ mice showed no effect on these juxtaglomerular populations (CB+: $t$ test $\mathrm{p}=0.629 ; \mathrm{CR}+:$-test $\mathrm{p}=0.487 ;$ Fig. $4 \mathrm{~F}, \mathrm{G})$.

Together, these data indicate that loss of COUP-TFI expression in the Emx1-lineage selectively affects adult generated DAergic cells, where it regulates TH expression, without altering their survival or expression of factors related to the DAergic lineage.

\section{Impaired Zif268 expression in COUP-TFIfl/fl ${ }^{\text {EmxI-Cre }}$ mice}

A possible explanation of the TH phenotype observed in the absence of COUP-TFI in the Emx1lineage, is that COUP-TFI inactivation could affect TH expression in OB DAergic cells through an activity-dependent mechanism. To address this hypothesis, we examined the level of expression of the immediate early gene Zif268 in the GL of COUP-TFIfl/fl ${ }^{\text {Emxl-Cre }}$ and control mice. Zif268 has been suggested to mediate TH activity-dependent expression in a subset of OB DAergic neurons (Akiba et al., 2009) and, importantly, previous studies have identified Zif268 as a possible target for COUP-TFI through direct interactions with Sp1 (Pipaon et al., 1999). Both COUP-TFIfl/fl ${ }^{\text {Emxl-Cre }}$ and control mice were tested in an experimental paradigm (modified from Vincis et al., 2012; Magavi et al., 2005; Fig. 5A) in which animals were maintained either in conditions of low odour exposure (basal) or acutely stimulated by an odour mix (stim). In COUP-TFIfl/fl ${ }^{\text {Emxl-Cre }}$ mice, we detected a lower density of juxtaglomerular cells expressing Zif268 compared to control mice in basal conditions (two-way ANOVA, $\mathrm{F}_{(3,9)}=124.41$, p<0,001; basal $f l /+$ vs basal $f l / f l^{E m x l-C r e}$, Tukey post-hoc $\mathrm{p}<0.001$; Fig. 5B,C,D). Although COUP-TFI $f l / f l^{\text {Emxl-Cre }}$ mice responded to the odour mix stimulation with an increase in the density of Zif268+ cells (basal $f l / f l^{\text {Emxl-Cre }}$ vs stim $f l / f l^{\text {Emxl-Cre }}$, Tukey post-hoc $\mathrm{p}<0.01$; Fig. 5B,E,F), the average value reached in mutants was considerably lower compared to that observed in control mice ( $\operatorname{stim} f l /+$ vs stim $f l / f l^{\text {Emxl-Cre }}$, Tukey post-hoc $\mathrm{p}<0.001$; Fig. 5B), indicating an impairment in juxtaglomerular cell activation both in basal conditions and upon acute odour stimulation. 


\section{COUP-TFI controls TH expression in mature DAergic cells through a cell autonomous}

\section{activity-dependent mechanism}

To further understand the mechanisms at the basis of the activity-dependent control of $\mathrm{TH}$ by COUP-TFI and assess whether the effects of COUP-TFI ablation observed in COUP-TFIfl/fl EmxI-Cre $^{\text {. }}$ were cell autonomous, we used a lentiviral vector approach. Based on previous reports indicating that RMS precursors give rise to significantly larger population of GL interneurons compared to SVZ precursors (Hack et al., 2005; Ihre and Alvarez-Buylla, 2011), a lenti-CRE-iGFP virus was injected into the RMS of the left hemisphere in adult COUP-TFIfl/fl mice, in order to inactivate COUP-TFI in a subset of juxtaglomerular cell progenitors/precursors (Fig. 6A-C). In parallel, the right hemispheres of the same mice were injected with control lenti-iGFP virus (Fig. 6A). Mice were then left to survive for 30 or 60 days post injection (dpi) before analysis (Fig. 6B). At both ages, GFP+ (Fig. 6F) and CRE+/GFP+ (Fig. 6J,K,N,O) cells were found in the GL, respectively in the right and left hemispheres of injected COUP-TFIfl/fl mice. In lenti-iGFP injected mice, the percentage of GFP+ cells double labelled for COUP-TFI ranged from nearly $24 \%$ to $36 \%$ at 30 and 60 dpi, respectively (30dpi, n=289 infected cells; 60dpi, n=366 infected cells; Fig. 6D,E-H). Importantly, the quantification of COUP-TFI+ cells in lenti-CRE-iGFP injected hemispheres showed no COUP-TFI immunoreactivity in CRE+/GFP+ cells (30dpi, n=183 infected cells; 60dpi, n=345 infected cells; Fig. 6D,I-L), indicating high efficiency of CRE-recombinase activity in infected cells. As control, we also injected lenti-CRE-iGFP viruses in wild type mice and found CRE+/GFP+ cells positive for COUP-TFI (30dpi: $35.28 \pm 4.08 \%, n=159$ injected cells; 60dpi: 44.2 $\pm 0.8 \%, \mathrm{n}=246$ injected cells), confirming the specificity of CRE activity in COUP-TFIfl/fl mice. In lenti-iGFP injected COUP-TFI $f l / f l$ mice, the percentage of double labelled TH+/GFP+ cells was about $21 \%$ and $36 \%$ at 30 and 60 dpi, respectively (30dpi n=289 cells; 60dpi n=366 cells; Fig. 6D,E-H,M-P), while the percentage of triple labelled TH+/COUP-TFI+/GFP+ cells was slightly lower (30dpi: $15.98 \pm 3.44 \%, \mathrm{n}=289$ infected cells; 60dpi: $25.63 \pm 0.99 \%, \mathrm{n}=366$ infected cells; 
Fig. 6D), in line with a large but incomplete co-expression between TH and COUP-TFI in juxtaglomerular cells (Fig. 1P,Q). Since we hypothesized a cell autonomous function for COUPTFI on TH, we expected a decrease in TH expression in the CRE+/GFP+ population of lenti-CREiGFP injected hemispheres. Accordingly, we observed a net reduction of TH expression in $\mathrm{CRE}+/ \mathrm{GFP}+$ cells at $60 \mathrm{dpi}$ (60dpi lenti-iGFP, $\mathrm{n}=366$ cells vs lenti-CRE-iGFP, $\mathrm{n}=345$ cells, $t$-test $\mathrm{p}<0.001$; Fig. 6D), but no difference in the percentage of $\mathrm{TH}+$ cells at 30dpi (30dpi lenti-iGFP, $\mathrm{n}=289$ cells vs lenti-CRE-iGFP, $\mathrm{n}=156$ cells, $t$-test $\mathrm{p}=0.379$; Fig. 6D). No differences were found in CR expression between lenti-iGFP and lenti-CRE-iGFP injected hemispheres (60dpi, lenti-iGFP: $43.4 \pm 2,1 \%, \mathrm{n}=208$ injected cells, lenti-CRE-iGFP: $45.6 \pm 3.5 \%, \mathrm{n}=177$ injected cells; $t$-test $\mathrm{p}=0.625)$, indicating that $\mathrm{CR}+$ cell type is not affected by the action of CRE.

Finally, we quantified the expression of Zif268 in GFP+ and CRE+/GFP+ cells (Fig. 7) and found a statistically significant decrease of Zif268+ cells in lenti-CRE-iGFP compared to lentiiGFP injected mice (60dpi, lenti-iGFP: $n=167$ injected cells; lenti-CRE-iGFP: $n=146$ injected cells; $t$-test $\mathrm{p}<0.05$; Fig. 7D). Together, these results strongly argue for a cell autonomous effect of COUP-TFI on the activity-dependent regulation of the DAergic phenotype.

\section{DISCUSSION}

In the present study, we demonstrate a novel key function of the nuclear receptor COUP-TFI in the maintenance of the DAergic phenotype in the adult OB. COUP-TFI has been thoroughly investigated in the developing forebrain (for review see Alfano et al., 2013), however only few data are available on COUP-TFI expression and function in the adult brain. Here, we address this issue focussing on the $\mathrm{OB}$, a highly plastic region of the adult mammalian brain, characterized by continuous neurogenesis (Lledo et al., 2008). We show that in the adult OB, as in the cerebral cortex (Lodato et al., 2011), COUP-TFI is expressed in distinct subpopulations of GABAergic interneurons. Little or no staining was observed in migrating neuroblasts, indicating that COUP-TFI expression in the OB is mostly associated to mature cells integrated in the GcL and GL. Thus, while 
COUP-TFI seems to be required in GABAergic neuron tangential migration in the developing cortex (Tripodi et al., 2004), our expression data indicate that COUP-TFI is unlikely to be involved in adult SVZ neuroblast migration.

OB interneurons include multiple subtypes (Parrish-Aungst et al., 2007) that derive from spatially restricted progenitors (Bovetti et al., 2007; Ihre and Alvarez Buylla, 2011). We focused on the GL to identify the phenotype of COUP-TFI-expressing cells and found that they largely belong to the DAergic lineage. Notably, the large majority of Pax6+ and TH+ cells in the GL are found to be positive for COUP-TFI, supporting possible specific functions for COUP-TFI in olfactory DAergic neurons. Interestingly, we observed that late postnatal and adult DAergic cells express COUP-TFI in much higher percentages compared to early neonatal DAergic cells, strongly indicating COUP-TFI implication in features peculiar to the function of the adult DAergic circuit.

It is well established that a mixture of intrinsic determination mechanisms and activitydependent cues are required for the DAergic phenotype acquisition and maintenance in the OB. Several transcriptional regulators, including Pax6, Er81, Dlx2 and Gsh2 are involved in OB DAergic neuron generation and specification, whereas on the other side sensory input is necessary for maintaining TH expression in DAergic cells (Cave and Baker, 2009). Our data show that COUP-TFI is mainly involved in the maintenance of TH through an activity-dependent mechanism, as demonstrated in our genetic and functional experiments.

The Cre-lox conditional knock-out mice in which COUP-TFI is selectively deleted in either the Dlx5/6- or the Emx1-progenitor lineage show a specific down-regulation of the $\mathrm{TH}+$ population exclusively in the Emx1-lineage, without affecting other juxtaglomerular cell types (i.e. CR+ or $\mathrm{CB}+$ cells). This was unexpected, since our previous analysis on cortical GABAergic interneuron populations, showed an imbalance between CR- and PV-expressing cortical interneurons in the absence of COUP-TFI in the Dlx5/6-lineage (Lodato et al., 2011). Lack of any significant changes in COUP-TFIfl/fl ${ }^{\text {Dlx5/6-Cre }}$ mice strongly suggest that this lineage only marginally contributes to COUP-TFI-expressing cells in the adult OB. Although we did not investigate whether COUP-TFI 
could act in other lineages involved in DAergic neuron generation (such as Gsh2-lineage; Young et al., 2007), our data clearly show that absence of COUP-TFI in Emx1-expressing progenitors (Merkle et al., 2007; Ventura and Goldman, 2007) has a strong effect on adult TH-expressing cells. This could be due to either to a problem in the generation/survival of DAergic cells or in the selective down-regulation of TH expression in these cells. Our birth-dating analysis showed no effect on the generation/survival of adult born OB interneurons, but instead we found a reduction in the number of BrdU+ cells that were double positive for $\mathrm{TH}$, in line with the observed decrease of $\mathrm{TH}+$ cells over the whole GL interneuron population. Moreover, no differences were found in the density of Pax6+ and Er81+ cells, or in the percentages of Pax6+/BrdU+ and Er81+/BrdU+ cells, in the GL of COUP-TFIfl/ff ${ }^{\text {Emxl-Cre }}$ mice. Thus, COUP-TFI deletion affects TH expression independently from Pax6 and/or Er81 regulation, suggesting that interneurons committed to the DAergic phenotype still remain in the olfactory GL, but just fail to express TH.

Based on these genetic findings and on the observations of COUP-TFI sensory dependent regulation in naris closure experiments, we hypothesised that this factor could be involved in mechanisms of activity-dependent modulation of TH expression. A direct effect of COUP-TFI on TH expression regulation is unlikely, since no consensus sequences for COUP-TFI were found in the TH promoter sequence (our unpublished in silico data). Instead, we hypothesized that COUPTFI could act through indirect mechanisms by controlling expression of genes related to odourevoked responses that in turn affect TH expression. Among the possible target genes, we focussed our interest on the immediate early gene Zif268, known as an activity-dependent regulator of inducible TH expression (Papanikolaou and Sabban 2000; Nakashima et al., 2003; Akiba et al., 2009; Kress and Wullimann, 2012; Bepari et al., 2012). We show that Zif268 induction is severely impaired in the GL of COUP-TFI mutant mice, both in basal condition and following acute odour stimulation, supporting a role for COUP-TFI in the control of OB interneuron responsiveness. It is possible that COUP-TFI acts on Zif268 promoter through interaction with other factors, such as Sp1 (Rohr et al., 1997), which has been previously demonstrated to be involved in Zif268 activation by 
COUP-TFI in other cellular systems (Pipaon et al., 1999). Further studies are needed to dissect the molecular interactions underlying Zif268 expression regulation by COUP-TFI.

We further demonstrate that COUP-TFI regulation on TH expression is cell-autonomous by deleting COUP-TFI through lentiviral injections. After 30 days, absence of COUP-TFI in infected neurons has no effect on TH expression, confirming that COUP-TFI is not involved in the intrinsic determination of DAergic phenotype acquisition. However, longer survival time (i.e. 60 days) shows a net drop in the percentage of TH-expressing cells among the infected population. Although lenti-CRE-iGFP injection in COUP-TFIfl/fl mice does not selectively target Emx1-derived progenitors, we initially showed that COUP-TFI-expressing juxtaglomerular interneurons mainly

derive from the Emx1-lineage and that TH down-regulation upon COUP-TFI loss is restricted to this lineage. We thus infer that the drop in the percentage of TH-expressing cells among the lentiCRE-iGFP infected population principally occurs in Emx1-derived juxtaglomerular cells.

Overall, our results show that COUP-TFI is involved in the maintenance, rather than establishment, of the DAergic phenotype. In addition, GFP-infected cells at 60 dpi also show reduced Zif268 expression, indicating impairment in cell responsiveness to sensory inputs and supporting a link between COUP-TFI function and activity-dependent regulation of TH expression.

In conclusion, this study reveals a novel function for COUP-TFI in the mouse forebrain, and gives new insights into our understanding of the mechanisms regulating DAergic neurons in the adult OB. Among the multiple factors required for the specification and proper differentiation of OB DAergic neurons (Cigola et al., 1998; Cave and Baker 2009, Akiba et al., 2010; Flames and Hobert 2011, Banarjee et al., 2013), we propose that COUP-TFI acts selectively in adult generated mature cells, where it cooperates to maintain $\mathrm{TH}$ expression in an activity-dependent manner (Fig.S1).

\section{REFERENCES}

Akiba, N., Jo, S., Akiba, Y., Baker, H., Cave, J.W. (2009). Expression of EGR-1 in a subset of olfactory bulb dopaminergic cells. J Mol Hisol. 40(2),151-5. 
Akiba, Y., Cave, J.W., Akiba, N., Langley, B., Ratan, R.R., Baker, H. (2010). Histone deacetylase inhibitors de-repress tyrosine hydroxylase expression in the olfactory bulb and rostral migratory stream. Biochem Biophys Res Commun. 393(4):673-7.

Alfano, C. and Studer, M. (2013). Neocortical arealization: Evolution, mechanisms, and open questions. Develop Neurobiol. 73,411-447.

Armentano M., Filosa A., Andolfi G., Studer M. (2006). COUP-TFI is required for the formation of commissural projections in the forebrain by regulating axonal growth. Development 133(21), 4151-62.

Armentano, M., Chou, S.J., Tomassy, G.S., Leingartner, A., O'Leary, D.D., Studer, M. (2007). COUP-TFI regulates the balance of cortical patterning between frontal/motor and sensory areas. Nat Neurosci. 10, 1277-1286.

Bagley, J., LaRocca, G., Jimenez, D.A., Urban, N.N. (2007). Adult neurogenesis and specific replacement of interneuron subtypes in the mouse main olfactory bulb. BMC Neurosci. 8,92

Baker, H., Morel, K., Stone, D.M., Maruniak, J.A. (1993). Adult naris closure profoundly reduces tyrosine hydroxylase expression in mouse olfactory bulb. Brain Res. 614,109-116.

Baker, H., Liu, N., Chun, H.S., Saino-Saito, S., Berlin, R., Volpe, B., Son, J.H. (2001). Phenotypic differentiation during migration of dopaminergic progenitor cells to the olfactory bulb. J. Neurosci. 21(21):8505-8513

Banerjee, K., Akiba, Y., Baker, H., Cave, J.W. (2013). Epigenetic control of neurotransmitter expression in olfactory bulb interneurons. Int J Dev Neurosci. 31(6):415-23.

Batista-Brito, R., Close, J., Machol, R. and Fishell, G. (2008). The distinct temporal origins of olfactory bulb interneuron subtypes. J. Neurosci. 28, 3966-3975.

Bovetti, S., Peretto, P., Fasol A., De Marchis, S. (2007). Spatio-temporal specification of olfactory bulb interneurons. J Mol Histol. 38(6),563-9.

Bovetti, S., Veyrac, A., Peretto, P., Fasolo, A., De Marchis, S. (2009). Olfactory enrichment influences adult neurogenesis modulating GAD67 and plasticity-related molecules expression in newborn cells of the olfactory bulb. PLOS ONE 4,e6359.

Bepari, A.K., Watanabe, K., Yamaguchi, M., Tamamaki, N., Hirohide, T. (2012). Visualization of odor-induced neuronal activity by immediate early gene expression. BMC Neurosci. 13,140

Brill, M.S., Snapyan, M., Wohlfrom, H., Ninkovic, J., Jawerka, M., Mastick, G.S., AsheryPadan, R., Saghatelyan, A., Berninger, B., Götz, M. (2008). A Dlx2- and Pax6-dependent transcriptional code for periglomerular neuron specification in the adult olfactory bulb. $J$ Neurosci. 28(25),6439-52.

Brown, J.P., Couillard-Despres, S., Cooper-Kuhn, C.M., Winkler, J., Aigner, L., Kuhn, H.G. (2003). Transient expression of doublecortin during adult neurogenesis. J Comp Neurol. 467,1-10.

Cave, J.W. and Baker, H. (2009). Dopamine systems in the forebrain. Adv Exp Me Biol. 651,1535. 
Cave, J.W., Akiba, Y., Banerjee, K., Bhosle, S., Berlin, R., Baker, H. (2010). Differential regulation of dopaminergic gene expression by Er81. J Neurosci. 30,4717-4724.

Cigola, E., Volpe, B.T., Lee, J.W., Franzen, L., Baker, H. (1998). Tyrosine hydroxylase expression in primary cultures of olfactory bulb: role of L-type calcium channels. J Neurosci. 18(19),7638-49.

de Chevigny, A., Core, N., Follert, P., Wild, S., Bosio, A., Yoshikawa, K., Cremer, H., Beclin, C. (2012). Dynamic expression of the pro-dopaminergic transcription factors Pax6 and Dlx2 during postnatal olfactory bulb neurogenesis. Front Cell Neurosci. 5,6:6.

De Marchis, S., Bovetti, S., Carletti, B., Hsieh, Y.C., Garzotto, D., Peretto, P., Fasolo, A., Puche, A.C., Rossi, F. (2007). Generation of distinct types of periglomerular olfactory bulb interneurons during development and in adult mice: implication for intrinsic properties of the subventricular zone progenitor population. J Neurosci. 27(3),657-664.

Flames, N., and Hobert, O. (2011). Transcriptional control of the terminal fate of monoaminergic neurons. Annu Rev Neurosci. 34,153-84.

Gorski, J.A., Talley, T., Qiu, M., Puelles, L., Rubenstein, J.L., Jones, K.R. (2002). Cortical excitatory neurons and glia, but not GABAergic neurons, are produced in the Emx1-expressing lineage. J Neurosci. 22,6309-6314.

Hack, M.A., Saghatelyan, A., de Chevigny, A., Pfeifer, A., Shery-Padan, R., Lledo, P.M., Götz, M. (2005). Neuronal fate determinants of adult olfactory bulb neurogenesis. Nat Neurosci. 8,865872.

Ihrie, R.A. and Alvarez-Buylla, A. (2011). Lake-front property: a unique germinal niche by the lateral ventricles of the adult brain. Neuron 70(4),674-86.

Kiyokage, E., Pan, Y.Z., Shao, Z., Kobayashi, K,. Szabo, G., Yanagawa, Y., Obata, K., Okano, H., Toida, K., Puche, A.C., Shipley, M.T. (2010). Molecular identity of periglomerular and short axon cells. J Neurosci. 30(3),1185-96.

Kohwi, M., Osumi, N., Rubenstein, J.L., Alvarez-Buylla, A. (2005). Pax6 is required for making specific subpopulations of granule and periglomerular neurons in the olfactory bulb. J. Neurosci. 25,6997-7003.

Kohwi, M., Petryniak, M.A., Long, J.E., Ekker, M., Obata, K., Yanagawa, Y., Rubenstein, J.L., Alvarez-Buylla, A. (2007). A subpopulation of olfactory bulb GABAergic interneurons is derived from Emx1- and Dlx5/6-expressing progenitors. J Neurosci. 27,6878-6891.

Kosaka, K. and Kosaka, T. (2007). Chemical properties of type 1 and type 2 periglomerular cells in the mouse olfactory bulb are different from those in the rat olfactory bulb. Brain Res. 1167,4255.

Knapska E. and Kaczmarek L. (2004). A gene for neuronal plasticity in the mammalian brain: Zif268/Egr-1/NGFI-A/Krox-24/TIS8/ZENK? Progress in Neurobiol 74(4),183-211.

Kress, S. and Wullimann, M.F. (2012). Correlated basal expression of immediate early gene egr1 and tyrosine hydroxylase in zebrafish brain and downregulation in olfactory bulb after transitory olfactory deprivation. J Chem Neuroanat. 46(1-2),51-66. 
Lin, F.J., Qin, J., Tang, K., Tsai, S.Y., Tsai, M.J. (2011). Coup d'Etat: an orphan takes control. Endocr Rev. 32(3),404-21.

Lledo, P.M., Merkle, F.T., Alvarez-Buylla, A. (2008). Origin and function of olfactory bulb interneuron diversity. Trends Neurosci. 31(8),392-400.

Lodato, S., Tomassy, G.S., De Leonibus, E., Uzcategui, Y.G., Andolfi, G., Armentano, M., Touzot, A., Gaztelu, J.M., Arlotta, P., Menendez de la Prida, L., Studer, M. (2011). Loss of COUP-TFI alters the balance between caudal ganglionic eminence- and medial ganglionic eminence-derived cortical interneurons and results in resistance to epilepsy. J. Neurosci. 31,46504662.

Luskin, M.B. (1993). Restricted proliferation and migration of postnatally generated neurons derived from the forebrain subventricular zone. Neuron 11,173-189.

Magavi, S.S., Mitchell, B.D., Szentirmai, O., Carter, B.S., Macklis, J.D. (2005). Adult-born and preexisting olfactory granule neurons undergo distinct experience-dependent modifications of their olfactory responses in vivo. J Neurosci. 25(46),10729-39.

Matsushita N., Okada H., Yasoshima Y., Takahashi K., Kiuchi K., Kobayashi K. (2002) Dynamics of tyrosine hydroxylase promoter activity during midbrain dopaminergic neuron development. J Neurochem. 82,295-304

Merkle, F.T., Mirzadeh, Z., Alvarez-Buylla, A. (2007). Mosaic organization of neural stem cells in the adult brain. Science 317,381-384.

Nakashima, A., Ota, A., Sabban, E.L. (2003). Interactions between Egr1 and AP1 factors in regulation of tyrosine hydroxylase transcription. Brain Res Mol Brain Res. 112(1-2),61-9.

Pallotto, M., Nissant, A., Fritschy, J.M., Rudolph, U., Sassoè-Pognetto, M., Panzanelli, P., Lledo, P.M. (2012). Early formation of GABAergic synapses governs the development of adultborn neurons in the olfactory bulb. J Neurosci. 32(26),9103-15.

Papanikolaou N.A. and Sabban E.L. (2000). Ability of Egr1 to activate tyrosine hydroxylase transcription in PC12 cells. Cross-talk with AP-1 factors. J Biol Chem. 275(35),26683-9.

Park, J.I., Tsai, S.Y., Tsai, M.J. (2003). Molecular mechanism of chicken ovalbumin upstream promoter-transcription factor (COUP-TF) actions. Keio J Med. 52,174-181.

Parrish-Aungst, S., Shipley, M.T., Erdelyi, F., Szabo, G., Puche, A.C. (2007) Quantitative analysis of neuronal diversity in the mouse olfactory bulb. J. Comp. Neurol. 501,825-836.

Pipaón, C., Tsai, S.Y., Tsai, M.J. (1999). COUP-TFI upregulates NGFI-A gene expression through an Sp1 binding site. Mol Cell Biol. 19(4),2734-45.

Prakash, Y.S., Smithson, K.G., Sieck, G.C. (1994). Application of the Cavalieri principle in volume estimation using laser confocal microscopy. Neuroimage 1,325-333.

Qiu, Y., Cooney, A.J., Kuratani, S., DeMayo, F.J., Tsai, S.Y., Tsai, M.J. (1994), Spatiotemporal expression patterns of chicken ovalbumin upstream promoter-transcription factors in the developing mouse central nervous system: evidence for a role in segmental patterning of the diencephalon. PNAS 91(10), 4451-5. 
Rohr, O., Aunis, D., Schaeffer, E. (1997) COUP-TF and Sp1 interact and cooperate in the transcriptional activation of the human immunodeficiency virus type 1 long terminal repeat in human microglial cells. J Biol Chem. 272(49):31149-55.

Saino-Saito, S., Cave, J.W., Akiba, Y., Sasaki, H., Goto, K., Kobayashi, K., Berlin, R., Baker, H. (2007). ER81 and CaMKIV identify anatomically and phenotypically defined subsets of mouse olfactory bulb interneurons. J. Comp. Neurol. 502,485-496.

Stenman, J., Toresson, H., Campbell, K. (2003). Identification of two distinct progenitor populations in the lateral ganglionic eminence: implications for striatal and olfactory bulb neurogenesis. J. Neurosci. 23,167-174.

Tamamaki, N., Yanagawa, Y., Tomioka, R., Miyazaki, J., Obata, K., Kaneko, T. (2003). Green fluorescent protein expression and colocalization with calretinin, parvalbumin, and somatostatin in the GAD67-GFP knock-in mouse. J Comp Neurol. 467,60-79.

Tripodi, M., Filosa, A., Armentano, M., Studer, M. (2004). The COUP-TF nuclear receptors regulate cell migration in the mammalian basal forebrain. Development 131,6119-6129.

Ventura, R.E., and Goldman, J.E. (2007). Dorsal radial glia generate olfactory bulb interneurons in the postnatal murine brain. J Neurosci. 27(16), 4297-303.

Vergaño-Vera, E., Yusta-Boyo, M.J., de Castro, F., Bernad, A., de Pablo, F., Vicario-Abejón, C. (2006). Generation of GABAergic and dopaminergic interneurons from endogenous embryonic olfactory bulb precursor cells. Development 133(21),4367-79.

Vincis, R., Gschwend, O., Bhaukaurally, K., Beroud, J., Carleton, A. (2012). Dense representation of natural odorants in the mouse olfactory bulb. Nat Neurosci. 15(4),537-9.

Young, K.M., Fogarty, M., Kessaris, N., Richardson, W.D. (2007). Subventricular zone stem cells are heterogeneous with respect to their embryonic origins and neurogenic fates in the adult olfactory bulb. J. Neurosci. 27,8286-8296.

\section{FIGURE LEGENDS}

Fig. 1 COUP-TFI distribution in the adult and postnatal OB.

$\boldsymbol{A}-\boldsymbol{D}$, Adult OB coronal sections stained in red for COUP-TFI and in green for NeuN (B), DCX (C) or GAD67-GFP (D); insets in B and C show double labelled cells in the GL; insets in $\mathrm{C}$ show confocal images of double labelled cells in the GL and GcL at higher magnification. E-I, Adult OB GL stained in red for COUP-TFI and in green for CR (E), CB (F), TH (G, inset: confocal image at higher magnification), GFP expressed under TH promoter (H) or Pax6 (I). $\boldsymbol{J}-\boldsymbol{M}$, OB GL at different 
postnatal ages (P0, J; P7, K; P14, L; P21, M) stained in red for COUP-TFI and in green for TH. Arrowheads: double labelled cells. In figure I, arrow indicates a Pax6+ cell negative for COUP-TFI. $\boldsymbol{N}-\boldsymbol{O}$, Quantification of TH+ cells $(\mathrm{N})$ and COUP-TFI+ cells $(\mathrm{O})$ at different postnatal ages. $\boldsymbol{P}-\boldsymbol{Q}$, Quantification of COUP-TFI and TH cells double-labelled for TH and COUP-TFI, respectively. Error bars indicate s.e.m. Tukey post-hoc; $* * * p<0.001$; ns: not significant, $\mathrm{p} \geq 0.05$. Scale bar in $\mathrm{D}=100 \mu \mathrm{m}$ and applies to A. Scale bar in insets in $\mathrm{D}$ and $\mathrm{G}=10 \mu \mathrm{m}$. Scale bar in $\mathrm{I}=50 \mu \mathrm{m}$ and applies to B,C,E,F,G,H. Scale bar in $\mathrm{M}=50 \mu \mathrm{m}$ and applies to J,K,L. GL: glomerular layer; EPL: external plexiform layer; GcL: granule cell layer.

\section{Fig. 2 Olfactory deprivation drastically decreases TH and COUP-TFI expression}

$\boldsymbol{A}$, OB stained for COUP-TFI (red) and TH (green) in control (A) and deprived (B) mice 42 days following unilateral naris closure. $\boldsymbol{C}$, Number of $\mathrm{TH}+$ cells in control and deprived mice. $\boldsymbol{D}$, Relative proportion of $\mathrm{TH}+$ (light grey) and $\mathrm{TH}$ - (dark grey) cells among the total number of COUP-TFI+ cells in control and deprived mice. Arrowheads: double labelled cells. Arrows: TH+/COUP-TFI- cells. Error bars indicate s.e.m. Student's $t$-test; ***p $<0.001$ Scale bar in B=50 $\mu \mathrm{m}$ and applies to A. GL: glomerular layer.

\section{Fig. 3 Ablation of COUP-TFI in Emx1-lineage affects TH expression in the OB}

$\boldsymbol{A}-\boldsymbol{I}$, OB stained in COUP-TFI (red, A,D,G), and for TH (green, B,E,H), merged in C,F,I; COUP-

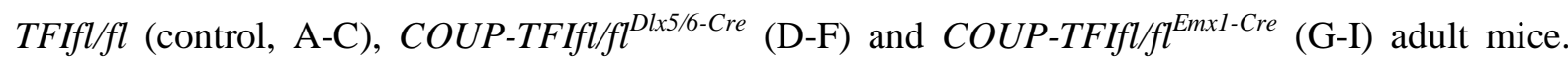
Scale bar in $\mathrm{I}=50 \mu \mathrm{m}$ and applies to A-H. $\boldsymbol{J}-\boldsymbol{K}$, Mean number of COUP-TFI+ cells (J) and TH+ cells (K) per squared millimetres in the GL of control (grey), COUP-TFIfl/fl ${ }^{\text {Dlx5/6-Cre }}$ (orange) and COUPTFIflffl $^{\text {Emxl-Cre }}$ (light blue) mice. Error bars indicate s.e.m. Tukey post-hoc; $* * * \mathrm{p}<0.001$.

Fig. 4 Ablation of COUP-TFI does not affect adult-born interneuron survival and does not influence expression of $\mathrm{OB}$ interneuron markers except TH

$A$, Mean number of BrdU+ cells per squared millimetres in the GL of control (grey), COUPTFIfl/fl $^{\text {Dlx5/6-Cre }}$ (orange) and COUP-TFIfl/fl ${ }^{\text {Emxl-Cre }}$ (light blue) mice 42 days following BrdU injection. $\boldsymbol{B}, \%$ of BrdU+ cells double-labelled for TH in the GL of control and COUP-TFIfl/fI EmxI- $^{\text {. }}$ ${ }^{C r e}$ mice. C, GL stained for TH (green) and BrdU (red). Inset shows a higher magnification of a resliced $\mathrm{TH}+/ \mathrm{BrdU}+$ cell. Scale bar in $\mathrm{C}=50 \mu \mathrm{m}$, in inset=10 $\mu \mathrm{m}$. $\boldsymbol{D}-\boldsymbol{G}$, Mean number of Pax6+(D), Er81+(E) $\mathrm{CB}+(\mathrm{F}), \mathrm{CR}+(\mathrm{G})$ cells per squared millimetres in the GL of control and COUPTFIfl/fl ${ }^{\text {Emxl-Cre }}$ mice. Error bars indicate s.e.m. Student's $t$-test; ${ }^{*} \mathrm{p}<0.05$. 
Fig. 5 Ablation of COUP-TFI in Emx1-lineage impairs Zif268 induction

$\boldsymbol{A}$, Protocol of acute odour stimulation. $\boldsymbol{B}$, Mean number of Zif268+ cells density in the GL of COUP-TFIfl/+ (grey) or COUP-TFIfl/fl ${ }^{\text {Emxl-Cre }}$ (light blue) mice in basal condition (BASAL) or following odour stimulation (STIM). C-F, GL stained in red for Zif268 in COUP-TFIfl/+ (C,E)

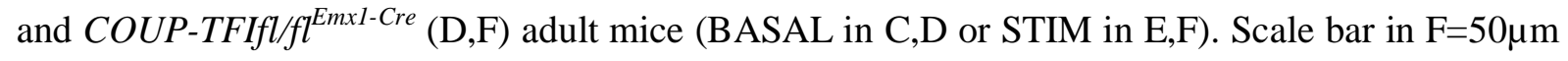
and refers to C-D. Error bars indicate s.e.m. Tukey post-hoc; **p $>0.01 ; * * * \mathrm{p}<0.001$.

Fig. 6 Lentiviral Cre-mediated deletion of COUP-TFI in adult-born juxtaglomerular cells decreases TH expression

$\boldsymbol{A}-\boldsymbol{C}$, Experimental protocol $\boldsymbol{A}$, Diagram of stereotaxic injections of lentiviral vectors expressing Cre recombinase and GFP (lenti-CRE-iGFP) or GFP only (lenti-iGFP) into the left and right hemispheres of adult COUP-TFI $f l f l$ mice respectively. $\boldsymbol{B}$, Infected cells were analysed in OB GL 30 and 60 days post injection (dpi). $\boldsymbol{C}$, Lentiviral injection triggers the infection of a subset of bulbar interneuron precursors in the rostral migratory stream (RMS, bottom panel). Infected cells are recognized as GFP+ (lenti-iGFP) or CRE+/GFP+ (lenti-CRE-iGFP) in ipsilateral OB GL (top panel) at the time of analysis. $\boldsymbol{D}, \%$ of COUP-TFI+ or TH+ cells among the total number of infected cells 30 and 60 dpi in the OB GL ipsilateral to lenti-iGFP or lenti-CRE-iGFP injections. $\boldsymbol{E}-\boldsymbol{H}$, Confocal images of the OB GL ipsilateral to lenti-iGFP injection stained for COUP-TFI (white, E), GFP (green, F) and TH (red,G). Arrow (H) indicates a triple-labeled cell. I-P, Confocal images of the OB GL ipsilateral to lenti-CRE-iGFP injection stained in white for COUP-TFI (I) or TH (M), in green for GFP $(J, N)$ and in red for Cre recombinase $(K, O)$. None of the injected cells $(\mathrm{GFP}+\mathrm{CRE}+$; arrows; J,K) express COUP-TFI (I), while triple labelled GFP+/CRE+/TH+ cells can be observed (arrow; M-P). Insets in E-P show higher magnification with confocal reslicing in H,L,P. Scale bar in $\mathrm{P}=50 \mu \mathrm{m}$ and refers to E-O. Scale bars in insers $\mathrm{H}, \mathrm{L}$ and $\mathrm{P}=10 \mu \mathrm{m}$. Error bars indicate s.e.m. Student's $t$-test; **p<0.01; ***p $<0.001$.

\section{Fig. 7 Lentiviral Cre-mediated deletion of COUP-TFI decreases Zif268 expression in adult-} born juxtaglomerular cells

$\boldsymbol{A}-\boldsymbol{C}$, Representative confocal resliced image of a Zif268+/GFP+ cell (C) stained for GFP (green, A) and Zif268 (red, B) in the OB GL. D, \% of Zif268+ cell among the GFP+ injected cells in the OB GL at 60dpi. Scale bar in $\mathrm{C}=50 \mu \mathrm{m}$ and refers to A,B. Error bars indicate s.e.m. Student's $t$-test; $* \mathrm{p}<0.05$. 
Fig. S1 Model of COUP-TFI involvement in activity-dependent TH expression in olfactory DAergic neurons.

$\boldsymbol{A}$, Olfactory deprivation triggers a down-regulation of COUP-TFI, Zif268 ${ }^{1}$ and TH expression in OB GL. B, Loss of COUP-TFI function decreases both Zif268 and TH in presence of normal sensory input. $\boldsymbol{C}$, Proposed model for COUP-TFI role in sensory-dependent regulation of TH expression in the adult OB: COUP-TFI controls the cellular responsiveness to sensory input by regulating either directly and/or indirectly the activity of immediate early genes such as Zif268 and in turn influences TH expression. ${ }^{1}$ Akiba et al., 2009; ${ }^{2}$ Kress and Wullimann, 2012; ${ }^{3}$ Akiba et al., 2010; ${ }^{4}$ Banerjee et al., 2013; ${ }^{5}$ Cigola et al., 1998. 
$\mathbf{A}_{\mathrm{u}}$

B

$14 \mathrm{C}$

$0^{\circ}$

GL

GL

$\begin{array}{l:l}E P L & G C L\end{array}$

COUP-TFi:

E $: x^{2}:$

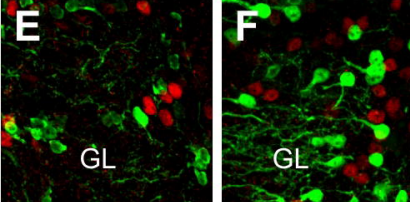

$\operatorname{lig}^{2}+x^{2}$

CR/GOUPTFI

$\mathbf{J}$

$+3$

ONL

1. $\mathrm{GL}$ $x+5,2$

THICOUPLTF

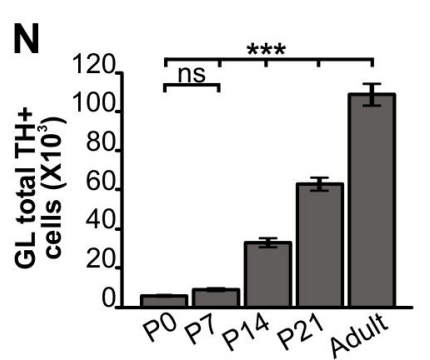

EPL ONL GL $\&$ EPL

THICOUP:TH:

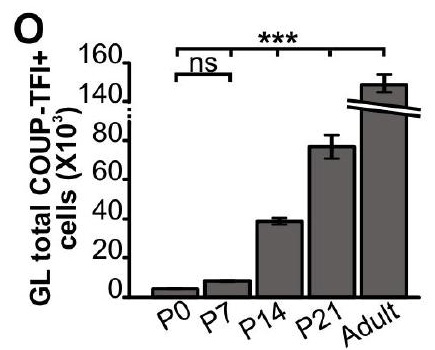

GcL

D

Neuv ar.

$\triangle$

e. 1

DCX P TF

$\mathrm{H}>$ (1)

$4-\operatorname{sog}, 4$

ONL $491 \%$ : EPL

4. GL

1. (n)

W. 5

TH/COUPSHEL

GL

is

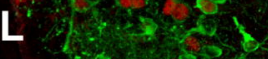

P14

cos

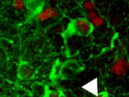

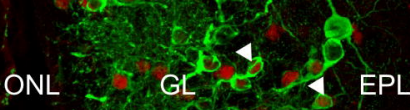

: 1 (1) 013

THICOUP-MFl $6 \mathrm{~s}$ s

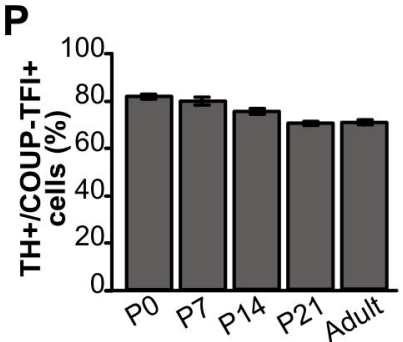

Q

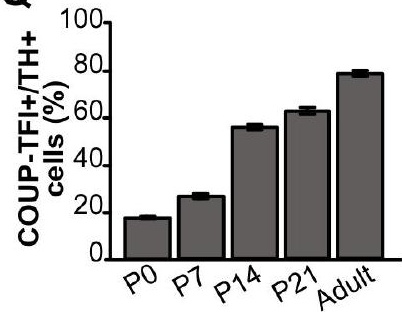



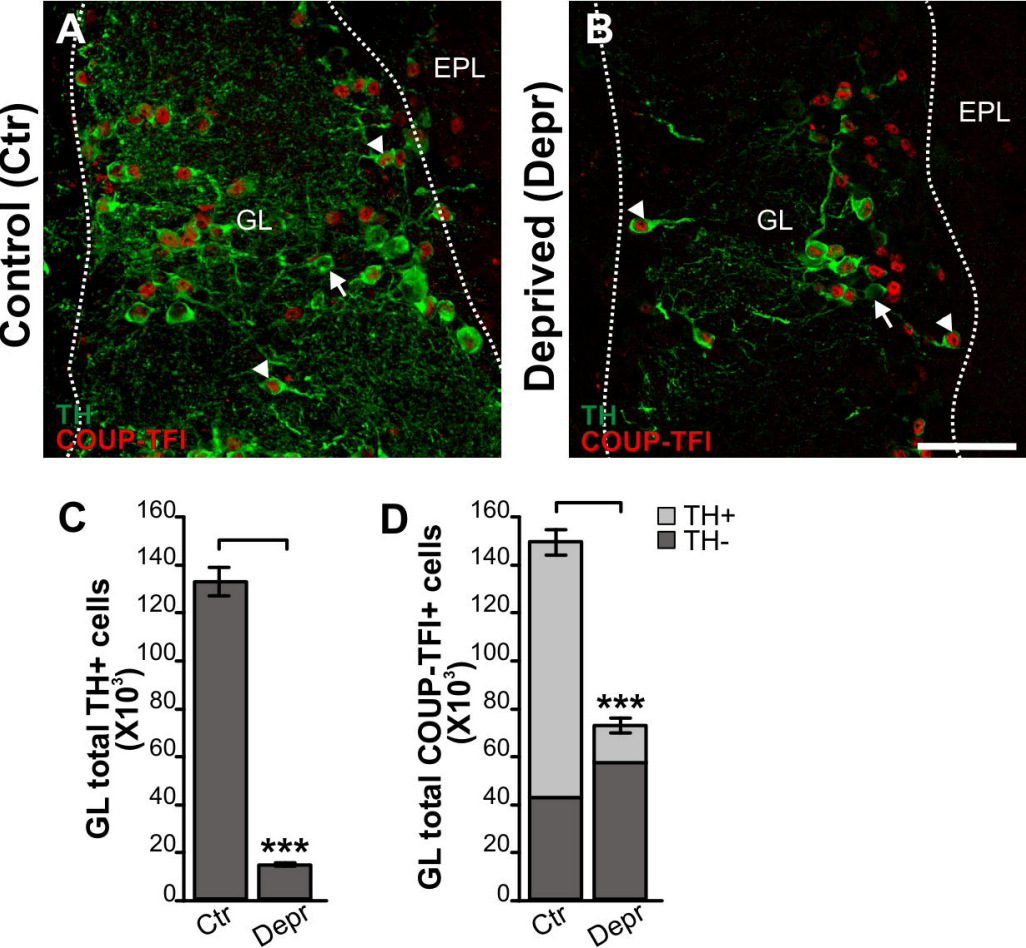

$\square$ TH+ 


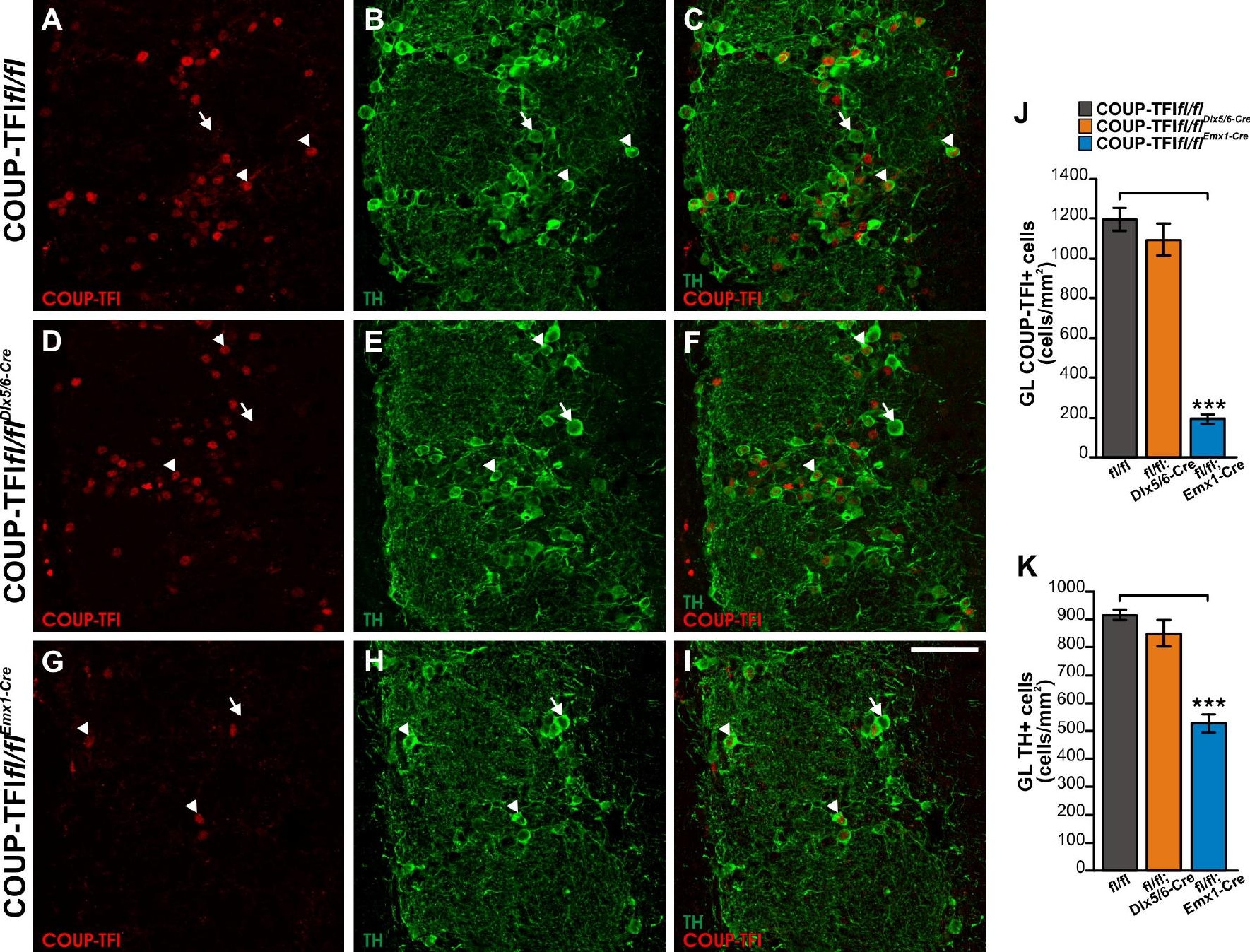


$\mathbf{A} y-1$
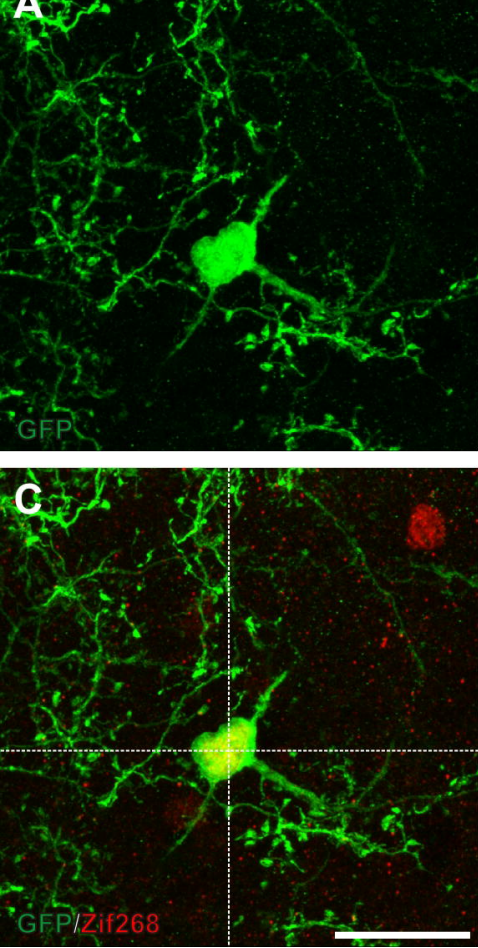

D

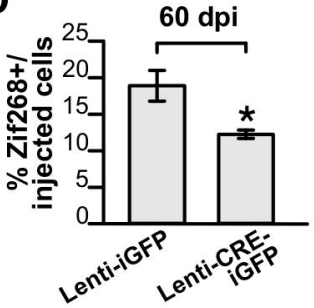

